\title{
Theoretical and Experimental Studies on Extraction of Carboxylic Acids from Aqueous Solution Using Ionic Liquids
}

\author{
Shitanshu Pandey, Neha Chomal, Suantak Kamsonlian, and Sushil Kumar
}

\begin{abstract}
This study is aimed to investigate the ability of ionic liquids (green solvents) for the recovery of various acids such as Itaconic-, Glycolic-, Tartaric-, Oxalic-, Propionic-, Lactic-, Acetic-, Acrylic-, Glyoxylic- and Nicotinic- acids from aqueous solutions as simulated fermentation broths. Selectivity and capacity of ionic liquids for extraction of acids are predicted by using the COSMOtherm software version C3.0 Release 12.01. $\mathrm{C}_{4} \mathrm{MIMTF}_{2} \mathrm{~N}$ is used as a model ionic liquid to verify the extraction ability of ionic liquids with experimental results. The effects of solvent, anions and cations of ionic liquids, and the length of carbon chain on the selectivity and capacity are also determined. The results indicate that sulfate anions in imidazolium based ionic liquids are comparatively better than other anions available in the database. It is also observed that with the increase in the length of carbon chain the selectivity decreases where as the capacity increases.
\end{abstract}

Index Terms - Ionic Liquids, extraction, carboxylic acids, equilibria, cosmotherm.

\section{INTRODUCTION}

Carboxylic acids are small organic acids with one or more carboxylic acid groups. These acids are currently produced either from petroleum-based feedstock through chemical synthesis or from carbohydrates via fermentation. By the mid-twentieth century, petrochemical processes had begun to replace biochemical routes, and they are now the primary industrial methods for manufacturing many carboxylic acids, including acetic, propionic, butyric, fumaric, malic, nicotinic and acrylic acids [1]. Their current industrial applications include uses as food acidulents and in the manufacture of polyester resins. They can also be used as building blocks for the synthesis of esters and biodegradable polymers. With the increasing oil price, concerns about oil supplies and environmental pollution caused by petrochemical processes, and consumer demand for natural food ingredients, there has been a high level of interest in producing carboxylic acids from renewable resources using bioprocesses. However, the traditional recovery process of carboxylic acids from fermentation broth is quite complicated. Conventionally, acid can be recovered by precipitating as calcium salt with calcium hydroxide. In this recovery scheme, calcium salt is precipitated, recovered by

Manuscript received December 1, 2017; revised February 9, 2018.

Shitanshu Pandey and Suantak Kamsonlian are with Department of Chemical Engineering, Motilal Nehru National Institute of Tehnology (MNNIT) Allahabad, India.

Neha Chomal and and Sushil Kumar are with Department of Chemical Engineering, Birla Institute of Technology and Science (BITS) Pilani, India (e-mail: sushilk2006@gmail.com). filtration and converted to acid by addition of sulphuric acid. In the present work, the reactive extraction of carboxylic acids produced via fermentation, which is an intensified version of liquid-liquid extraction is studied [2]-[8].

Recently, ionic liquids are regarded as the potential solvents in the separation and purification industry. Ionic liquids are made up of ions and have properties such as negligible vapour pressure, high electrochemical window and wide temperature control range [9], [10]. Properties of these new class solvents can be modified by changing the structure of cation and anions. Conductor like screening model for real solvents (COSMO-RS) is used for investigating the ionic liquid systems for extraction of various acids. COSMO-RS calculations are performed using the COSMOtherm program, which is based on the theory of interacting surface charges of the molecules [11], [12]. It is better approach than group contribution methods because it requires no experimental data for the calculation of thermodynamic parameters. It is also used for screening of ionic liquids and determining their properties. The ionic liquid screening panel in COSMOtherm software facilitates the calculation of selectivity and capacity of ionic liquids. In the present study, the ability of ionic liquids to recover various acids such as acetic-, propionic-, butyric-, lactic-, itaconic and nicotinic acids from aqueous solutions as simulated fermentation broths is determined. The study is focussed to find the best combination of anion and cation of ionic liquid for a particular carboxylic acid. $\mathrm{C}_{4} \mathrm{MIMTF}_{2} \mathrm{~N}$ is used as a model ionic liquid to verify the extraction ability of ionic liquids for various organic acids from aqueous medium.

\section{THEORY}

COSMO-RS is a predictive method for thermodynamic equilibrium of fluids and liquid mixtures that uses a statistical thermodynamics approach based on the results of quantum chemical calculations. In a virtual conductor environment the solute molecule induces a polarization charge density on the molecular surface. These charges act back on the solute and generate a more polarized electron density than in vacuum. During the quantum chemical (QC) self-consistency algorithm, the solute molecule is thus converged to its energetically optimal state in a conductor with respect to electron density. The molecular geometry can be optimized using the same methods for calculations in vacuum. The polarization charge density or screening charge density of the COSMO calculation is a good local descriptor of the molecular surface polarity, hydrogen 
bonding and lipophilicity or hydrophilicity and is used to extent the model towards "Real Solvents". Screening of ionic liquids comprising cations such as phosphonium and 1-alkyl-3-methyl imidazolium (alkyl: methyl, ethyl, propyl, butyl, pentyl, hexyl, heptyl and octyl) and also include anions methyl sulfate, ethyl sulfate, butyl sulfate, octyl sulfate and bis-trifluoromethanesulfonimide $\left(\mathrm{TF}_{2} \mathrm{~N}\right)$. All the COSMO-RS calculations are done using COSMOtherm software version C21_0111 with the thermodynamics properties determined using BP_TZVP_C30_1201 parameterization. TZVP basis set COSMO database was used for all the components to estimate the activity coefficients of all the components [13].

The selectivity and capacity are computed at infinite dilution using these equations:

Selectivity at infinite dilution given by Eq. (1)

$$
S_{12}^{\infty}=\frac{\gamma_{2}^{\infty}}{\gamma_{1}^{\infty}}
$$

Capacity at infinite dilution is calculated by Eq. (2)

$$
C_{1}^{\infty}=\frac{1}{\gamma_{1}^{\infty}}
$$

where, $\gamma_{1}^{\infty}$ and, $\gamma_{2}^{\infty}$ are the activity coefficients at infinite dilution of solute 1 and solute 2 in ionic liquids respectively.

\section{EXPERIMENTAL}

1-Butyl-4-methylimidazolium bistrifluoromethanesulfonimide $\left(\mathrm{C}_{4} \mathrm{MIMTF}_{2} \mathrm{~N}\right)$ with a purity of 99.0\%, used as extractant was procured by Sigma-Aldrich, USA. The carboxylic acids (Itaconic-, Glycolic-, Tartaric-, Oxalic-, Propionic-, Lactic-, Acetic-, Acrylic-, Glyoxylicand Nicotinic acid) of AR grade procured from Spectrochem Pvt Ltd. India. All compounds are used without any pretreatment. Aqueous phase solutions with a concentration, $0.125 \mathrm{~mol} . \mathrm{L}^{-1}$ of nicotinic acid and $0.25 \mathrm{~mol} . \mathrm{L}^{-1}$ of other acids were prepared using distilled water. The pure ionic liquid $\left(\mathrm{C}_{4} \mathrm{MIMTF}_{2} \mathrm{~N}\right)$ is used for extraction with an organic to aqueous phase volume ratio of 1:5. The extraction process is followed by 12 hours stirring using temperature controlled reciprocating shaker bath at $200 \mathrm{rpm}$ and $25^{\circ} \mathrm{C}$. After achieving equilibrium, the phases get settled for 1 hour 30 minutes. The analysis of aqueous phase is done by titration using $0.05 \mathrm{M} \mathrm{NaOH}$ solution.

\section{RESUlts AND Discussion}

The capacity indicates the amount of ionic liquid required for the separation of a desired product from the solute solvent system. Higher capacity means that the amount of ionic liquid required for extraction is less. The selectivity will explain the affinity of an ionic liquid towards desired product. An ionic liquid having higher capacity and selectivity is preferred for liquid-liquid extraction [14]-[15].

The extraction process is also analyzed by means of the degree of extraction and distribution coefficient. The distribution coefficient, $K_{D}$, is calculated using Eq. 3.

$$
K_{\mathrm{D}}=\frac{\bar{C}_{\mathrm{HA}}}{C_{\mathrm{HA}}}
$$

where, $\bar{C}_{\mathrm{HA}}$ is the total concentration of carboxylic acid in organic phase and $C_{\mathrm{HA}}$ is the total acid concentration (dissociated and un-dissociated) in aqueous phase at equilibrium.

The degree of extraction is defined as the ratio of acid concentration in the extracted phase to the initial acid concentration in aqueous solution by assuming no change in volume at equilibrium given by Eq. 4 .

$$
E=\frac{K_{D}}{1+K_{D}} \times 100
$$

Itaconic Acid

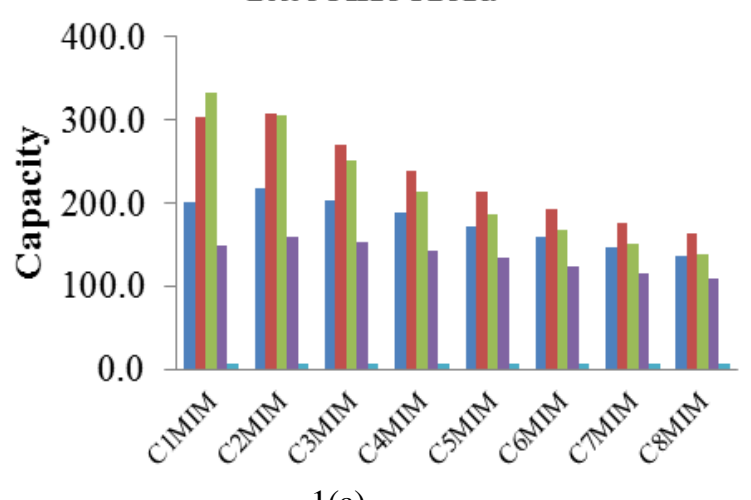

1(a)

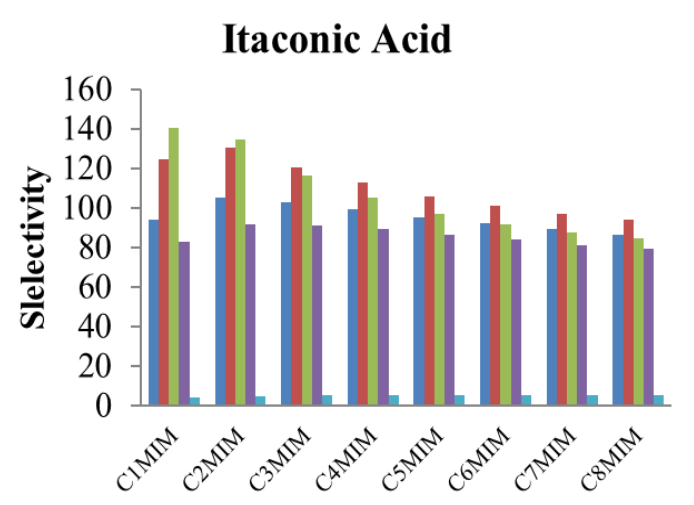

1(b)

Fig. 1. Capacity and selectivity of 1-alkyl-3-methylimidazolium ionic liquids for Itaconic acid in aqueous phase.

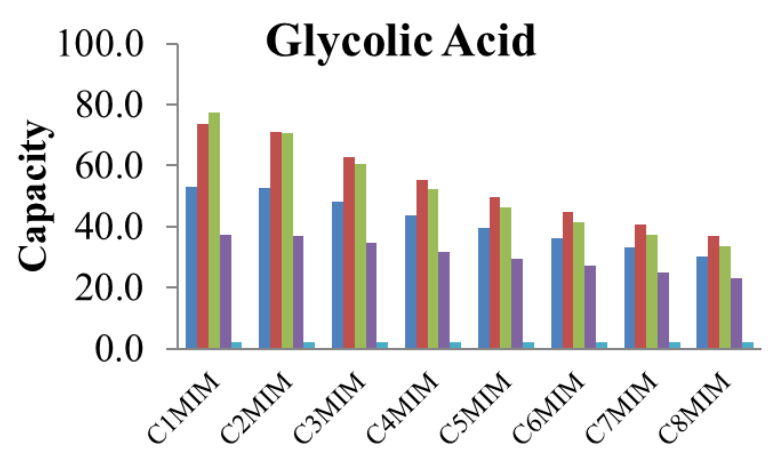

2(a) 


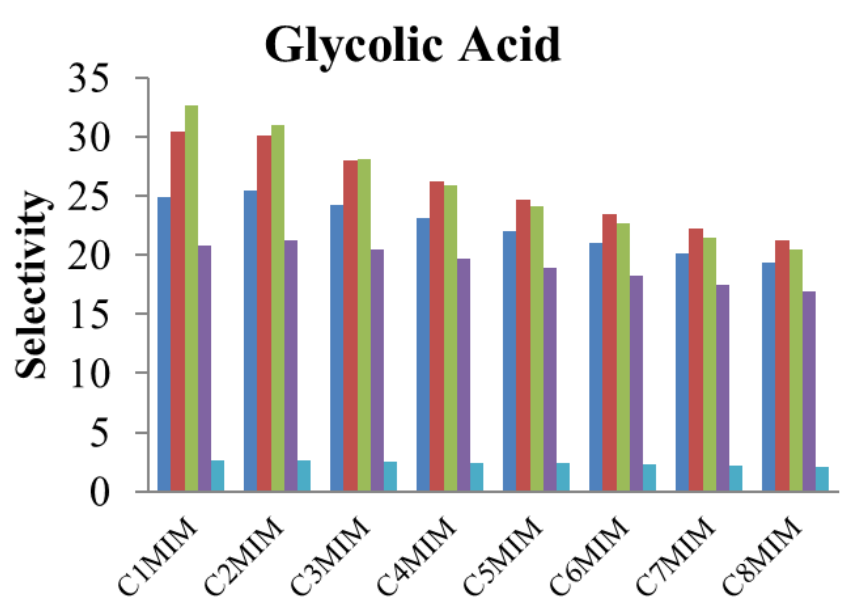

2(b)

Fig. 2. Capacity and selectivity of 1-alkyl-3-methylimidazolium ionic liquids for Glycolic acid in aqueous phase.

\section{TheORETICAL RESUlts}

To study the capacity and selectivity of 1-alkyl-3methylimidazolium ionic liquids ( $\mathrm{C}_{1}$ to $\mathrm{C}_{8}$ alkyl group) for extraction of different carboxylic acids (Itaconic-, Glycolic, Tartaric-, Oxalic-, Propionic-, Lactic-, Acetic-, Acrylic-, Glyoxylic- and Nicotinic acid) in aqueous phase, the COSMOtherm software is used and the predicted data are shown in Fig. 1-10, respectively. The following anions are used to find the same from Fig. 1-10.

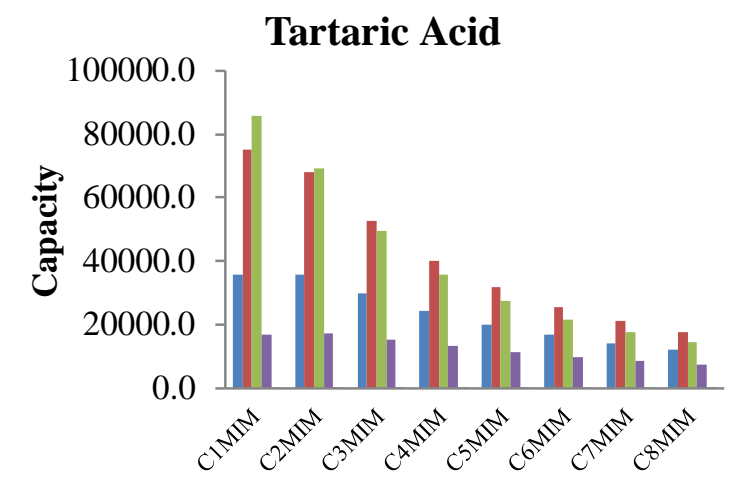

3(a)

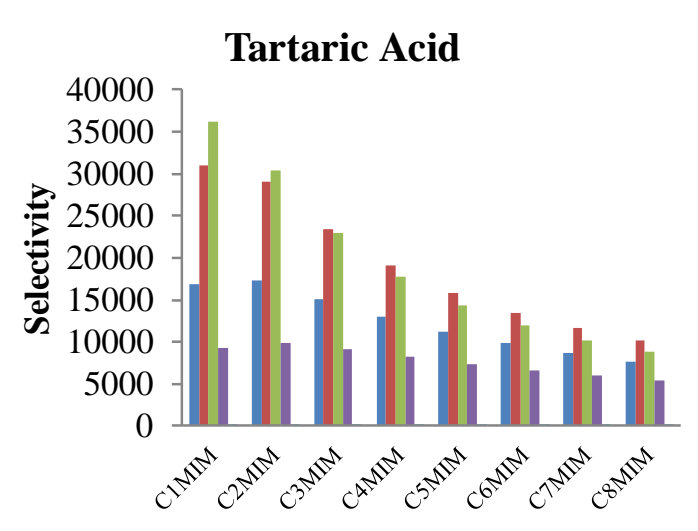

3(b)

Fig. 3. Capacity and selectivity of 1-alkyl-3-methylimidazolium ionic liquids for Tartaric acid in aqueous phase.
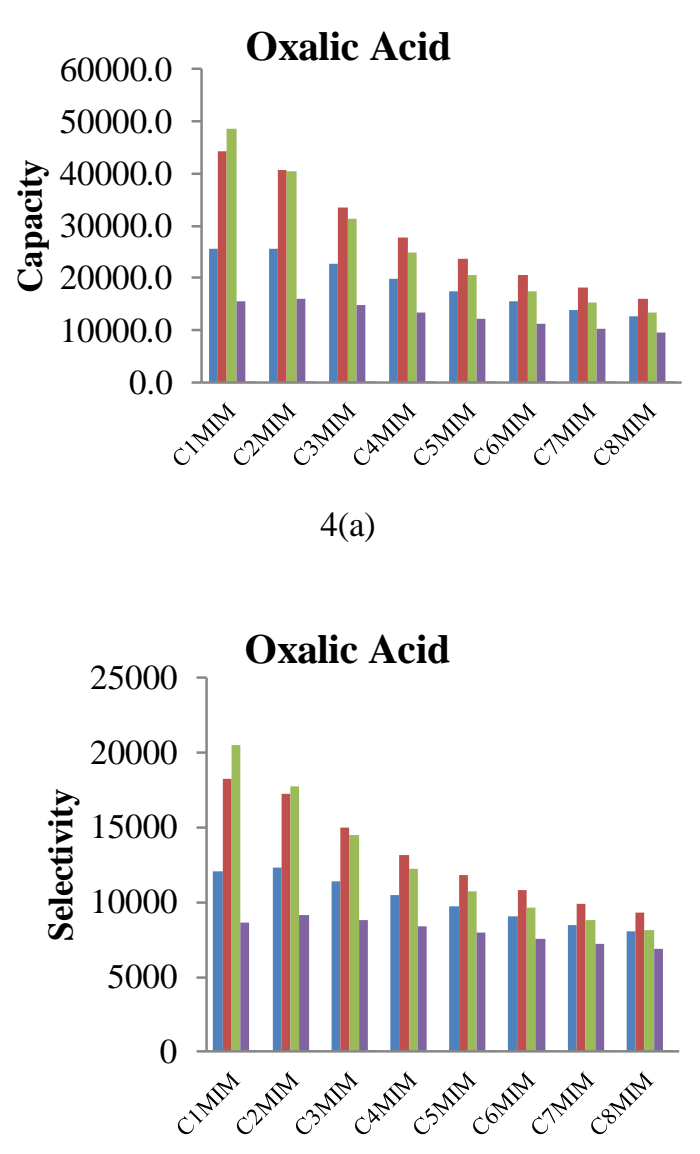

4(b)

Fig. 4. Capacity and selectivity of 1-alkyl-3-methylimidazolium ionic liquids for Oxalic acid in aqueous phase.

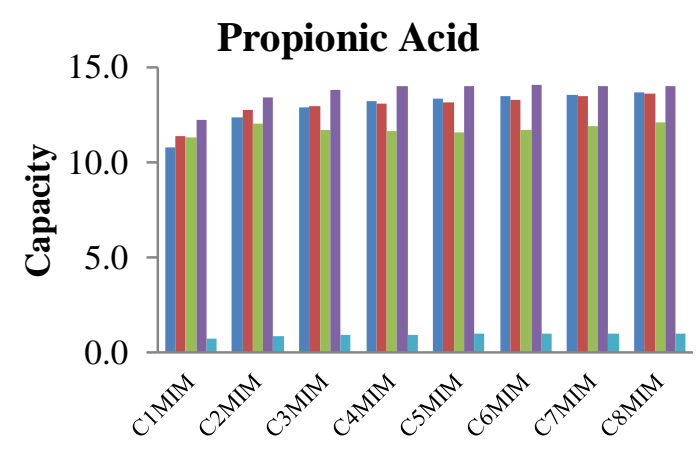

5(a)

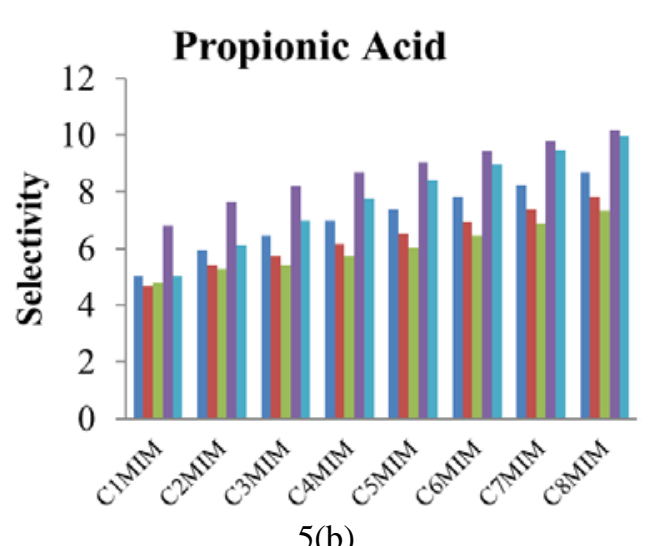

Fig. 5. Capacity and selectivity of 1-alkyl-3-methylimidazolium ionic liquids for Propionic acid in aqueous phase. 


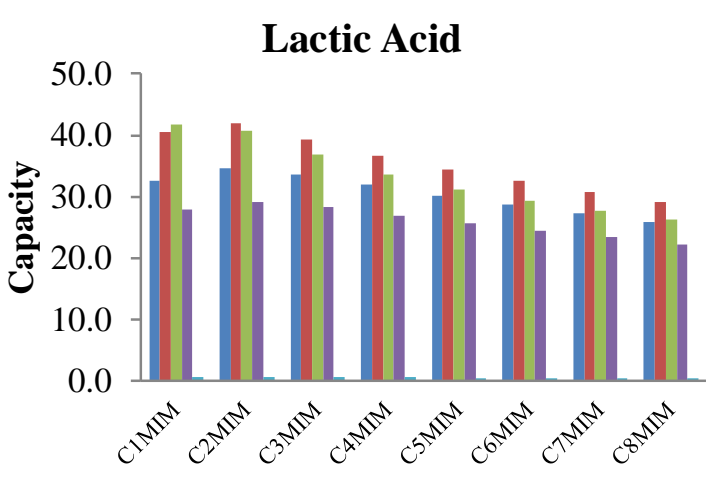

6(a)

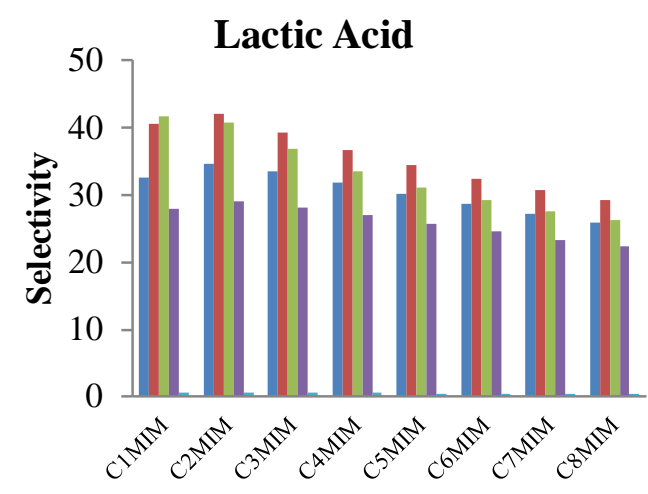

6(b)

Fig. 6. Capacity and selectivity of 1-alkyl-3-methylimidazolium ionic liquids for lactic acid in aqueous phase.

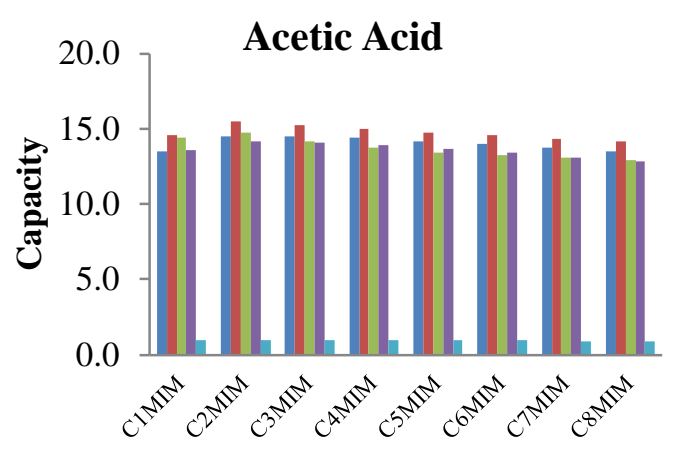

$7(\mathrm{a})$

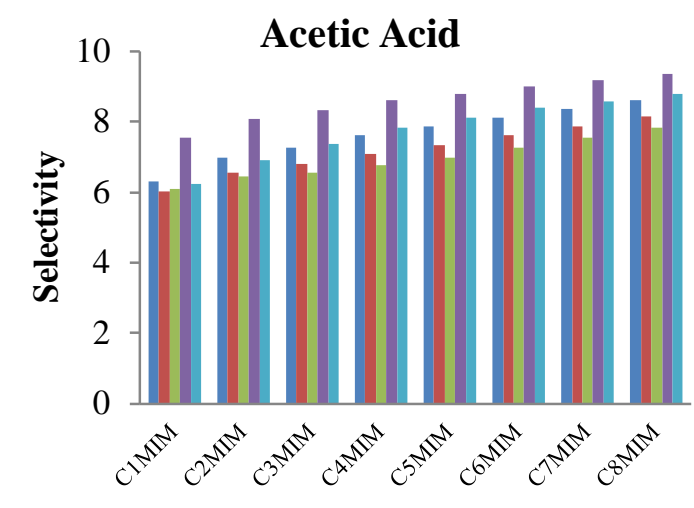

7(b)

Fig. 7. Capacity and selectivity of 1-alkyl-3-methylimidazolium ionic liquids for acetic acid in aqueous phase.

\section{Acrylic Acid}

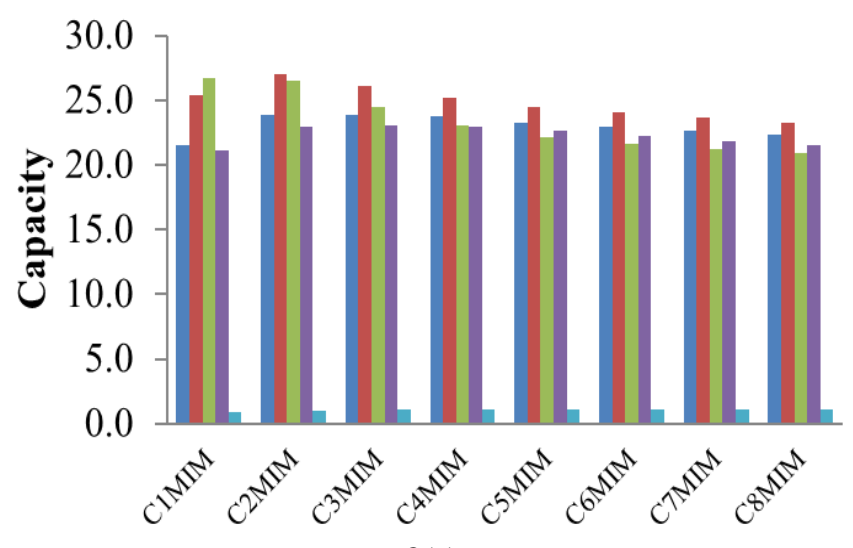

8(a)

\section{Acrylic Acid}

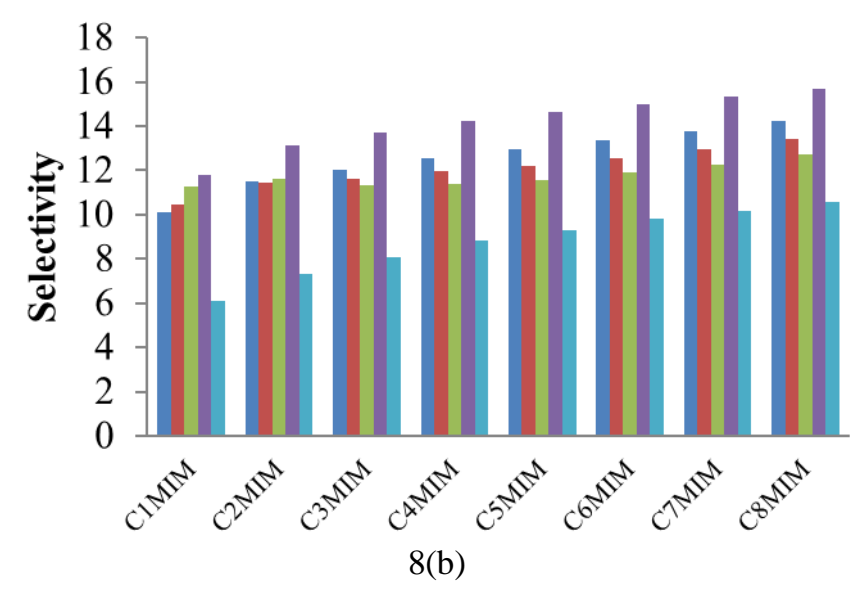

Fig. 8. Capacity and selectivity of 1-alkyl-3-methylimidazolium ionic liquids for acrylic acid in aqueous phase.

Carboxylic acids (Itaconic acid, Glycolic acid, Tartaric acid, Oxalic acid, Propionic acid, Lactic acid, Acetic acid, Acrylic acid, Glyoxylic acid and Nicotinic acid) of 0.00125 $\mathrm{mol} / 5 \mathrm{ml}$ concentration in aqueous phases (water concentration $0.2755 \mathrm{~mol} / 5 \mathrm{ml}$ ) and ionic liquid $\left(\mathrm{C}_{4} \mathrm{MIMTF}_{2} \mathrm{~N}\right)$ of $0.00341 \mathrm{~mol} / \mathrm{ml}$ concentration is used for theoretical analysis of calculating distribution coefficients and degrees of extraction using COSMOtherm software. The predicted data for capacity, selectivity and degree of extraction, $E$ are given below in Table I. The respective analysis graphs are shown in Fig. 11 (a) and 11 (b).

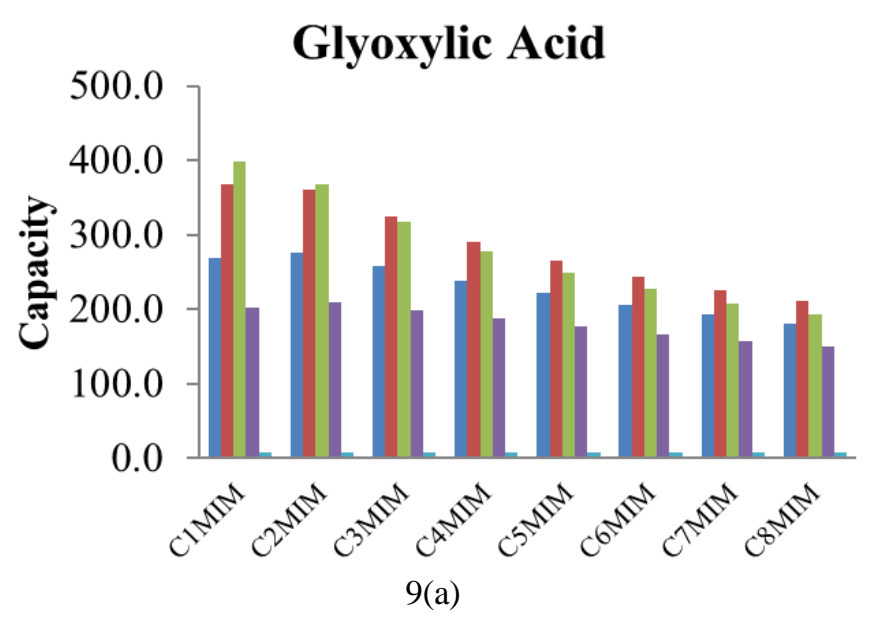




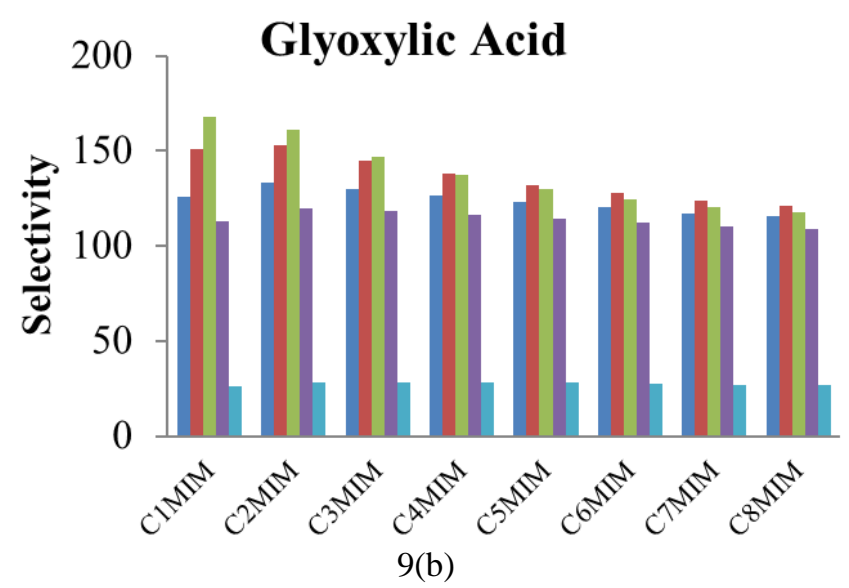

Fig. 9. Capacity and selectivity of 1-alkyl-3-methylimidazolium ionic liquids for glyoxylic acid in aqueous phase.
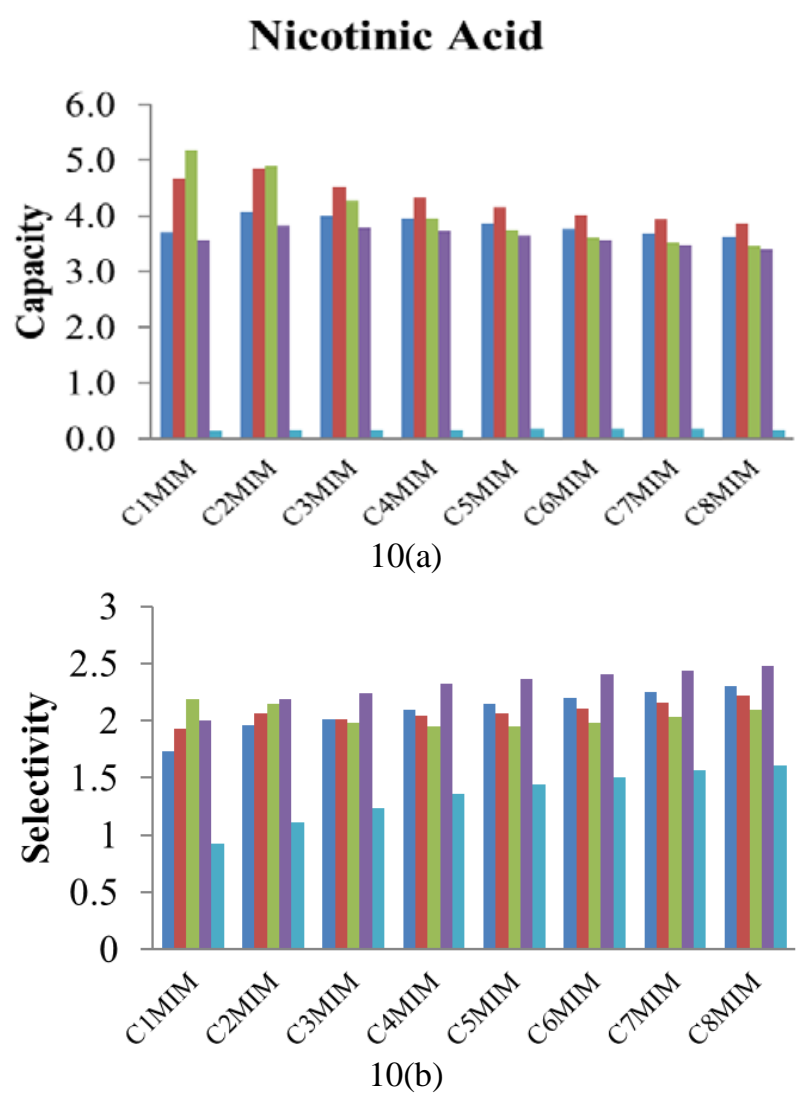

Fig. 10. Capacity and selectivity of 1-alkyl-3-methylimidazolium ionic liquids for nicotinic acid in aqueous phase.

TABLE I: CAPACITY, SELECTIVITY AND DEGREE OF EXTRACTION, E VALUES FOR EXTRACTION WITH $\mathrm{C}_{4} \mathrm{MIMTF}_{2} \mathrm{~N}$ IONIC LIQUID

\begin{tabular}{|c|c|c|c|}
\hline Acid & Capacity & Selectivity & E (\%) \\
\hline Itaconic acid & 0.65 & 5.28 & 90.90 \\
\hline Glycolic acid & 0.30 & 2.45 & 28.06 \\
\hline Tartaric acid & 1.65 & 13.42 & 21.29 \\
\hline Oxalic acid & 8.22 & 66.91 & 15.58 \\
\hline Propionic acid & 0.96 & 7.78 & 95.89 \\
\hline Lactic acid & 0.53 & 0.51 & 81.36 \\
\hline Acetic acid & 0.96 & 7.82 & 87.80 \\
\hline Acrylic acid & 1.08 & 8.82 & 95.30 \\
\hline Glyoxylic acid & 3.48 & 28.28 & 89.50 \\
\hline Nicotinic acid & 0.16 & 1.61 & 96.53 \\
\hline
\end{tabular}

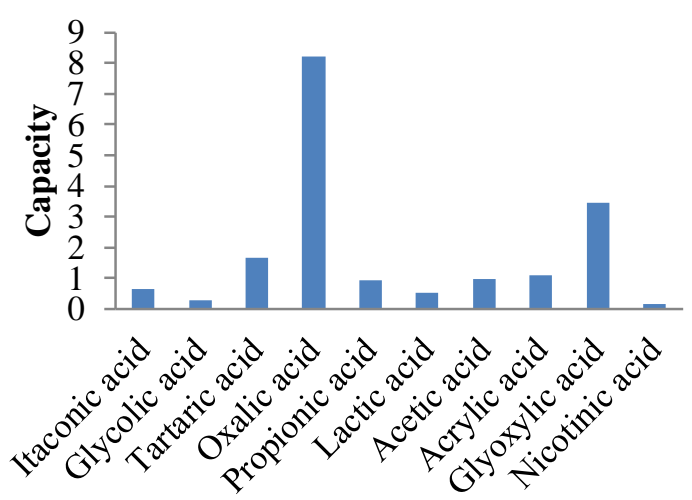

11(a)

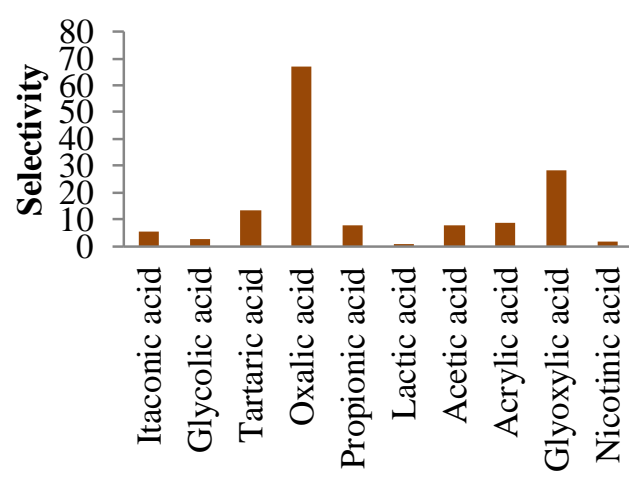

11(b)

Fig. 11. Capacity and selectivity for extraction of different carboxylic acids with $\mathrm{C}_{4} \mathrm{MIMTF}_{2} \mathrm{~N}$ ionic liquid.

\section{EXPERIMENTAL RESULTS}

Carboxylic acids (Itaconic acid, Glycolic acid, Tartaric acid, Oxalic acid, Propionic acid, Lactic acid, Acetic acid, Acrylic acid, Glyoxylic acid, $0.25 \mathrm{M}$ and Nicotinic acid, $0.125 \mathrm{M})$ in aquous phase and ionic liquid $\left(\mathrm{C}_{4} \mathrm{MIMTF}_{2} \mathrm{~N}\right)$ of $0.00341 \mathrm{~mol} / \mathrm{ml}$ concentration is used for experimental analysis of extraction. The extraction process is followed by 12 hours stirring using reciprocating shaker bath at $200 \mathrm{rpm}$ and $25^{\circ} \mathrm{C}$. After that to achieve equilibrium 1 hour 30 minutes is provided to samples to settle down. The analysis of aqueous phase is done by titration using $0.05 \mathrm{M} \mathrm{NaOH}$ solution. The distribution coefficient $\left(K_{\mathrm{D}}\right)$ and degree of extraction are given below in Table II, also the respective analysis graphs are shown in Fig. 12. The experimental results have shown also similar extraction trends for all acids using $\mathrm{C}_{4} \mathrm{MIMTF}_{2} \mathrm{~N}$ as extracting media.

TABLE II: EXPERIMENTAL VALUES OF DISTRIBUTION COEFFICIENT, (KD) AND DEGREE OF EXTRACTION, E

\begin{tabular}{|c|c|c|}
\hline Acid & $\boldsymbol{K}_{\mathbf{D}}$ & $\mathbf{E} \mathbf{( \% )}$ \\
\hline Itaconic acid & 1.35 & 87.11 \\
\hline Glycolic acid & 0.05 & 20.82 \\
\hline Tartaric acid & 0.05 & 20.82 \\
\hline Oxalic acid & 0.03 & 11.27 \\
\hline Propionic acid & 1.50 & 88.24 \\
\hline Lactic acid & 0.67 & 76.92 \\
\hline Acetic acid & 1.22 & 85.94 \\
\hline Acrylic acid & 2.33 & 92.11 \\
\hline Glyoxylic acid & 1.22 & 85.94 \\
\hline Nicotinic acid & 2.51 & 92.63 \\
\hline
\end{tabular}




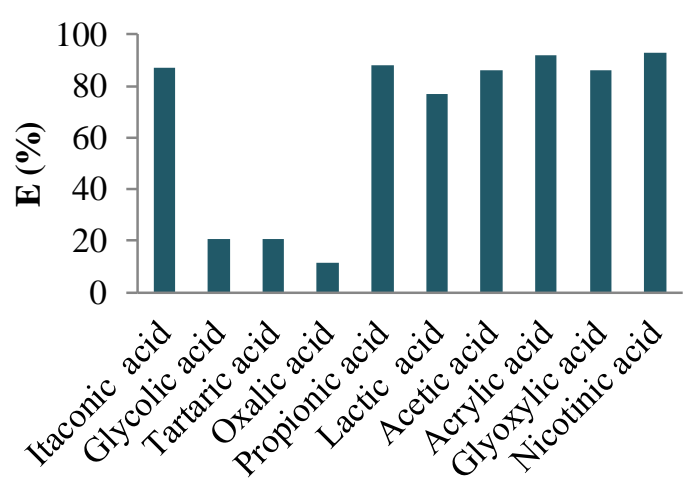

Fig. 12. Experimental values of degree of extraction of different carboxylic acids with $\mathrm{C}_{4} \mathrm{MIMTF}_{2} \mathrm{~N}$ ionic liquid.

\section{CONCLUSIONS}

COSMO-RS proved to be an efficient tool for screening of ionic liquids ${ }^{8}$ and for predicting their properties. It was found that the selectivity is highest in case of ionic liquids based on imidazolium cations. According to the results obtained it was found that octyl sulfate and butly sulfate are preferred for capacity and bis-trifluoromethanesulfonimide for selectivity. This software is further used for the generation of liquid-liquid equilibrium data and to determine the distribution coefficients and degree of extraction. Significant extraction is found for the acrylic acid, propoinic acid, itaconic acid, glyoxylic acid and nicotinic acid. These results are supported by experimental study. This study will also provide a framework to design experiments for maximum recovery of the products at different conditions.

\section{ACKNOWLEDGEMENT}

Department of Science and Technology (DST), India, for funding a research project under Fast track scheme for Young Scientist, SR/FTP/ETA-25/2011, Reactive Extraction of Nicotinic- and Isonicotinic Acids from Aqueous Solution (PI: Dr. Sushil Kumar, MNNIT, Allahabad, India).

\section{REFERENCES}

[1] A. S. Kertes and C. J. King, "Extraction chemistry of fermentation product carboxylic acid," Biotechnology and Bioengineering, vol. 28, pp. 269-282, 1986.

[2] S. Kumar and B. V. Babu, "Process intensification for separation of carboxylic acids from fermentation broths using reactive extraction," J. Fut. Eng. Technol., vol. 3, p. 19, 2008.

[3] A. S. Kertes and C. J. King, "Extraction chemistry of fermentation product carboxylic acids,” Biotechnol. Bioeng, vol. 28, p. 269, 1986.

[4] S. Kumar and B. V. Babu, "Process intensification of nicotinic acid production via enzymatic conversion using reactive extraction," Chem. Biochem. Eng. Q, vol. 23, p. 367, 2009.

[5] A. Keshav, K. L. Wasewar, and S. Chand, “ Extraction of acrylic, propionic, and butyric acid using Aliquat 336 in oleyl alcohol, Equilibria and effect of temperature," Ind. Eng. Chem. Res., vol. 48, no. 2, pp. 888-893, 2009.

[6] D. Datta and S. Kumar, "Reactive extraction of pyridine carboxylic acids with N, N-dioctyloctan-1-amine: Experimental and theoretical studies,” Sep. Sci. Technol., vol. 48, p. 898, 2013.

[7] S. Kumar, H. Uslu, D. Datta, S. Rarotra, and K. Rajput, "Investigation of extraction of 4-oxopentanoic acid by n,n-dioctyloctan-1-amine in six different diluents: equilibrium study,” J. Chem. Eng. Data, vol. 60, pp. 1447-1453, 2015.

[8] D. Datta, M. E. Marti, H. Uslu, and S. Kumar, "Extraction of levulinic acid using tri- $\mathrm{n}$-butyl phosphate and tri- $\mathrm{n}$-octylamine in 1octanol: Column design,” J. Taiwan Institute of Chemical Engineers, vol. 66, pp. 407-413, 2016.

[9] X. Han and D. W. Armstrong, "Ionic liquids in separations," Accounts of Chemical Research, vol. 40, no. 11, pp. 1079-1086, 2007.

[10] L. Moity, M. Durand, A. Benazzouz, C. Pierlot, V. Molinier, and J. M. Aubry, "Panorama of sustainable solvents using the COSMO-RS approach,” J. Green Chemistry, vol. 14, pp. 1132-1145, 2012.

[11] F. Eckert and A. Klamt, "Fast solvent screening via quantum chemistry: COSMO-RS approach,” AIChE Journal, vol. 48, pp. 369385, 2002.

[12] A. Klamt, "Conductor-like Screening model for real solvents: A new approach to the quantitative calculation of solvation phenomena," The Journal of Physical Chemistry, vol. 99, pp. 2224-2235, 1995.

[13] A. Klamt and G. Schuurmann, "COSMO: A new approach to dielectric screening in solvents with explicit expressions for the screening energy and its gradient," Journal of the Chemical Society, Perkin Transactions 2, vol. 5, pp. 799-805, 1993.

[14] L. Kumar, T. Banerjee, and K. Mohanty, "Prediction of selective extraction of cresols from aqueous solutions by ionic liquids using theoretical approach,” Separation Science and Technology, vol. 46, pp. 2075-2087, 2011.

[15] N. Chomal, A. Kumar, and S. Kumar, “Investigation of ionic liquid systems for extraction of benzoic acid from hydrocarbons," 2014AIChE Annual Meeting, Atlanta (GA) USA, November 16-21, 2014.

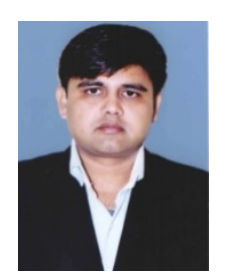

Sushil Kumar is an assistant professor in Department of Chemical Engineering at Motilal Nehru National Institute of Technology (MNNIT), Allahabad has over 13 years of industrial, teaching, and research experience. He did his B. Tech. in chemical engineering from Harcourt Butler Technological Institute (HBTI) - Kanpur, M. Tech. in chemical engineering from Indian Institute of Technology (IIT) - Kanpur and Ph.D from BITS - Pilani. He was awarded research project by Department of Science and Technology (DST), New Delhi, India under Fast Track Scheme for Young Scientists. He has also completed one research project funded by TEQIP-II, MNNIT Allahabad.

His current research interests include process intensification, nano biomaterials, waste water treatment, green technology, biochemical engineering and renewable energy sources. He is having around 100 research publications (36 journals, 59 conferences and 5 book chapters) to his credit which have been published over the years in various International and National Journals and Conference Proceedings. He has supervised 03 Ph.D scholars and 07 masters and currently supervising 04 Ph.D scholars and 2 masters. Dr. Kumar is a member of Editorial Board of international/national Journals 'International journal of Thermodynamics and Chemical Kinetics', "Recent Trends in Chemical Engineering" \& "Journal of Catalysts and Catalysis." He is a referee and expert reviewer of more than 20 International Journals of repute.

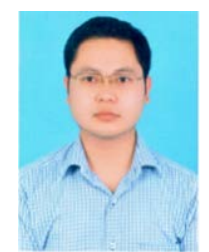

Suantak Kamsonlian did his B.Tech in the Department of Chemical Engineering from Kerala University, India. He has completed his M.Tech degree and Ph.D degree from IIT Roorkee in the Department of Chemical Engineering.

He has published numerous number of research papers in referred journals and presented many research papers in national and international conferences. He was also awarded as Young Researcher (National level competition) at YRC conference at ICT, Mumbai and nominated for Young Scientist, India. He has a working experienced of 2 years as a safety auditor at Cholamandalam Risk Services Pvt. Ltd., Chennai. At present, he is working at Motilal Nehru National Institute of Technology (MNNIT) Allahabad as an assistant professor in Chemical Engineering Department. He is also working with a projects funded by TEQIP, DST and various agencies. His area of expertise and interest includes environmental science and engineering, industrial hazard and safety management, wastewater treatment, electrochemistry, biochemical engineering, design and optimization of chemical processes. He can be reached at suantakk@mnnit.ac.in. 